\title{
New competition in Germany
}

A highly unorthodox new funding program is keeping German research universities on their toes these days. The 'Excellence Initiative' challenges universities to map out their areas of strength and their path to world-level excellence in any field. Despite its idiosyncrasies, this innovative-even audacious — scheme should inject some muchneeded competition and diversification (not to mention a considerable amount of new funding) into Germany's staid higher education system.

The Excellence Initiative is the newest attempt to address German academia's anxieties about playing second fiddle to Anglo-American universities. Nearly all German universities are public and funded at roughly equivalent levels by their home states. They cater mostly to students from the region and cannot cherry-pick their students or charge tuition. The system makes decent education available to all, but does not foster world-class institutions. Top science in Germany is done mostly at the Max Planck institutes, not the universities, and an Ivy League type of education is not available anywhere.

Dreams of a 'German Harvard' abound nevertheless. In 2004, the federal minister in charge of science and education called for the founding of "elite universities." The proposal elicited outrage, as it violated two principles of German politics: the equal distribution of benefits across regions and the sovereignty of the states over education. A year of ugly political bickering ensued, but surprisingly ended in an innovative proposal, approved by all parties, to identify and boost the best of the existing universities. Even after a bruising election and change of government in 2005, the program is still on track.

Launched in July 2005, the Excellence Initiative is run by scientists, with politicians on the deciding committee in a clear minority. It promises to provide $€ 1.9$ billion ( $\$ 2.4$ billion) over five years. The annual budget of Germany's main scientific funding agency, the DFG, has hovered around $€ 1.3$ billion ( $\$ 1.7$ billion) for the last several years, so the Excellence Initiative means serious money for the competition's winners. In two rounds of competition, a few universities will be awarded an average of $€ 21$ million (\$27 million) each in annual support for the best "Future Concepts." Consolation prizes will be given for about 40 new graduate school proposals ( $€ 1 / \$ 1.3$ million annually) and about 30 “Excellence Cluster" projects (€6.5/\$8.4 million annually). This funding is promised for at least five years, with renewal depending on fiscal and political circumstances.

By far the most novel, exciting and unsettling aspect of the Excellence Initiative is its wide-open character. The Future Concepts competition, in particular, contrasts starkly with the familiar DFG grant programs. Universities were asked to be creative and think outside the established boxes and hierarchies. "Anything goes as long as it's compatible with the Constitution," says Sabine Behrenbeck of the Wissenschaftsrat (Scientific Council), which runs the program together with the DFG. Furthermore, the initiative is open to all fields of university research, encompassing engineering, humanities and social, life and physical sciences. Accordingly, the spectrum of invited full proposals ranges from a graduate school for "Humanities and Theology" in Göttingen and an Excellence Cluster titled "Governance in a Globalized World" in Berlin to "Cognition for Technical Systems" in Munich and "Integrative Neuroscience" in Tübingen. There simply are no objective and transparent criteria by which one could weigh and compare the quality and international competitiveness of such disparate, wide-ranging proposals, causing understandable consternation among scientists accustomed to the usual grantapplication procedures. The DFG has issued helpful instructions and sample proposals. Behrenbeck admits, though, that-given the novelty of the program - "the decision process is being invented as we go."

For the first round, universities had to send draft proposals by late September (for the less ambitious projects) or mid-October (for the Future Concepts), busting a lot of summer vacation plans. Seventy-four universities submitted almost 300 draft proposals for graduate schools and Excellence Clusters and 27 drafts for Future Concepts (which must include at least one new graduate school and one Excellence Cluster). In January, 36 universities were invited to submit full proposals for graduate schools and/or Excellence Clusters, and 10 of them also received invitations to submit full proposals for Future Concepts, due in April. Referee panels, including international experts, will confer over the summer, with final decisions planned for October.

The outcome of the first-phase decision has raised some hackles, as expected. The great majority of successful draft proposals come from the natural sciences and engineering; only about $15 \%$ focus on humanities and social sciences. Among the ten universities allowed into the Future Concepts competition, nine are in the former West Germany, and the tenth is a university in former West Berlin. Among the other 26 universities invited to submit less ambitious full proposals, only 3 are in formerly East German territory. The geographically skewed outcome of the competition is tough to accept for politicians and residents from the eastern region. To make matters worse (and the well-known, but rarely acknowledged, regional gradients in academic power obvious), seven of ten Future Concept contenders are located in the two southern states of Baden-Württemberg and Bavaria. If the final decisions reflect this preliminary result, it will fly in the face of the hallowed principle of regional 'proportionality'. However, Behrenbeck and a scientist on the deciding committee (who asked to remain unnamed) vehemently assert that politics will not influence the final result.

Despite its potential value to German universities, this bold new program is not likely to create an equivalent to Harvard (which, for comparison, has an endowment of over \$25 billion/€19.5 billion). In Germany, endowments and private fundraising for universities are almost unheard of; indeed, the tax code stands in the way of large-scale philanthropy. However, assuming that the additional funds are distributed well, the initiative should provide a strong incentive for universities to find new paths to academic excellence while upholding the valued principle of equal opportunity in education. 